\title{
Olhar ecológico das crianças sobre o processo de aprendizagem nos anos iniciais do Ensino Fundamental
}

\section{Ecological view of children on the learning in the initial years of Fundamental Education}

\section{Mirada ecológica de los niños en el proceso de aprendizaje en los primeros años de la Educación Básica}

\author{
Marcia Soares da Silva ${ }^{1}$ \\ Narjara Mendes Garcia ${ }^{1}$
}

DOI: http://dx.doi.org/10.20435/serie-estudos.v22i45.1039

\begin{abstract}
Resumo: As crianças podem expressar as suas vivências dentro do ambiente escolar e através dessa manifestação, algumas demonstraram um "olhar ecológico". Através desse olhar, as crianças podem conhecer o mundo e transformar esse conhecimento em consciência e prática social. O presente estudo teve como objetivo investigar a percepção e interpretação das crianças acerca do processo de escolarização e os sentimentos diante da aprovação e reprovação nos primeiros anos do Ensino Fundamental. Foi realizada uma pesquisa qualitativa com vinte e três crianças do terceiro ano, através de estratégias lúdicas e conversas gravadas. Os resultados dessa pesquisa apontam que as crianças percebem as adversidades enfrentadas no processo de escolarização e sabem expressar os sentimentos de sucesso diante da aprovação ou frustração com a reprovação no primeiro ciclo dos anos iniciais do Ensino Fundamental. As crianças entendem que a reprovação pode ocorrer pela falta de esforço e estudo do educando, assim como problemas e ausência de apoio dos familiares. Diferentemente do que muitos adultos acreditam, as crianças têm um olhar e constroem expectativas a respeito da situação na qual estão imersas e sabem apontar o que pode ser melhor para elas.
\end{abstract}

Palavras-chave: educação ambiental; olhar ecológico; escola; pesquisa com crianças.

Abstract: Children can express their experiences within the school environment and through this manifestation, some have demonstrated an "ecological look". Through this look children can know the world and transform that knowledge into social awareness and practice. The present study aimed to investigate the perception and interpretation of the children about the schooling process and the feelings about the approval and disapproval in the first years of elementary school. A qualitative research was carried out with twenty- three children of the third year, through play strategies and recorded conversations. The results of this research indicate that children perceive the adversities

${ }^{1}$ Universidade Federal do Rio Grande (FURG), Rio Grande, Rio Grande do Sul, Brasil. 
faced in the schooling process and know how to express their feelings of success in the face of approval or frustration with the disapproval in the first cycle of the elementary school years. The children understand that disapproval may be due to lack of effort and study of the student, as well as problems and lack of support from family members. Contrary to what many adults believe, children have a look at and build expectations about the situation in which they are immersed and can point out what may be best for them.

Key words: environmental education; ecological look; school; research with children.

Resumen: Los niños pueden expresar sus experiencias en el ámbito escolar ya través de esta manifestación, algunos han demostrado una "mirada ecologica". Por medio de esta aspecto los niños pueden conocer el mundo y convertir este conocimiento en la conciencia y la práctica social. Este estudio tiene como objetivo investigar la percepción e interpretación de los niños sobre el proceso de la educación y sentimientos antes de la aprobación y desaprobación en los primeros años de la escuela primaria. una investigación cualitativa con veinte y tres hijos del tercer año, a través de estrategias lúdicas y conversaciones grabadas se llevó a cabo. Los resultados de esta investigación demuestran que los niños se dan cuenta de las dificultades que enfrentan en el proceso de aprendizaje y saben cómo expresar los sentimientos de éxito en la aprobación o la frustración con el fracaso en el primer ciclo de los primeros años de la escuela primaria. Los niños entienden que el no puede ocurrir por falta de esfuerzo y estudio del alumno, así como los problemas y la falta de apoyo familiar. A diferencia de muchos adultos creen que los niños tienen un aspecto y construyen las expectativas sobre la situación en la que están inmersos y saben señalar lo que puede ser mejor para ellos.

Palabras clave: educación ambiental; mirada ecológica; escuela; la investigación con niños.

\section{INTRODUÇÃO}

O presente artigo é um recorte de uma dissertação e apresenta uma pesquisa com crianças do terceiro e quarto anos iniciais do Ensino Fundamental, para compreender como elas vivenciam e pensam seu próprio processo de escolarização. Ao participarem das atividades de coletas de dados, as crianças foram incentivadas a falarem a respeito das suas vivências dentro do ambiente escolar e, através dessa manifestação, algumas demonstraram um "olhar ecológico". Destacamos esse olhar ecológico como uma percepção acerca do entorno e sobre sua relação com o ambiente ecológico (BRONFENBRENNER, 1996). Bronfenbrenner (1996) faz referência a esse olhar como uma perspectiva ecológica, em que o sujeito atribui ao mundo uma interpretação e a capacidade de compreensão da realidade a partir de dimensões (pessoa, processo, contexto e tempo) e sistemas interligados (micro e macrossistema) que influenciam e são influenciados pelo ser humano em desenvolvimento.

As crianças possuem sua "leitura de mundo" e essa interpretação da realidade deve ser reconhecida e respeitada. Desse modo, a educação transformadora 
e promotora da "alfabetização ambiental"2 é aquela que apresenta aos sujeitos possibilidade de desenvolverem o senso crítico e o pertencimento social para atuar no mundo e transformá-lo. Ela faz com que o educando estimule sua curiosidade e se perceba como um protagonista nos contextos em que se insere. Freire (1996) explicita sobre a curiosidade:

A curiosidade como inquietação indagadora, como inclinação ao desvelamento de algo, como pergunta verbalizada ou não, como procura de esclarecimento, como sinal de atenção que sugere e alerta faz parte integrante do fenômeno vital. Não haveria criatividade sem a curiosidade que nos move e que nos põe pacientemente impacientes diante do mundo que não fizemos, acrescentando a ele algo que fazemos. (FREIRE, 1996, p. 18).

Ao iniciar o processo de escolarização, as crianças apresentam múltiplas curiosidades, pensamentos, maneiras de brincar, falar e escutar. Através da curiosidade, elas podem conhecer o mundo para transformar o conhecimento em consciência e prática social. A escola deve priorizar reflexões e questionamentos sobre a realidade, em um processo de crítica e autocrítica, de política e conscientização coletiva (LOUREIRO, 2006 ).

O grande desafio da escola e dos educadores sempre foi promover a reflexão e a compreensão sobre a sociedade e as interações sociais, principalmente diante da complexidade das problemáticas ambientais existentes. O professor tem duas opções: ignorar ou trazer essas problemáticas para o debate e tentar, junto com o conhecimento de seus educandos, superar situações de seu cotidiano, como preconceito, discriminação, diversos tipos de exclusão, desigualdade social, entre outros. Tarefa importante, portanto, é não se fazer alheio às distintas problemáticas que acontecem no bairro, na cidade, no país e no mundo. O professor tem que ser um sujeito crítico, que convide seus educandos a perceberem o mundo através de uma forma crítica e com um olhar mais humano e cuidadoso perante a vida.

No senso comum, a criança em idade de escolarização é percebida como um pré-cidadão, no entanto a criança é cidadã desde o momento que nasce e se insere no mundo como sujeito de direitos. De acordo com Delgado e Muller (2006, p. 17):

[...] Evidentemente, este antes não é cronológico; significa uma anterioridade ontológica: o aluno é institucionalmente investido sobre um ser social concreto, a criança, cuja natureza biopsicosocial é incomensuravelmente mais complexa

\footnotetext{
${ }^{2}$ Utilizamos esse termo para destacar o processo de constituição do sujeito crítico/reflexivo e o surgimento do sentimento de pertencimento ao mundo para transformá-lo.
} 
do que o estatuto que adquire quando entra na escola.

As crianças têm sua própria espontaneidade, porém, ao mesmo tempo em que admiram essa capacidade, os adultos promovem regras para obter o controle de suas crianças. A escola é uma dessas instituições, raramente se vê uma escola arquitetada em que sejam considerados os interesses e necessidades infantis e, sim, muito longe disso, escolas elaboradas para o domínio e a disciplina. Ainda é distante o reconhecimento da contribuição das crianças para a produção do conhecimento (DELGADO; MULLER, 2006 ).

A cultura da criança é construída a partir de atividades chamadas "reproduções interpretativas" (CORSARO, 2011), que significa que a criança não só representa o que vê, mas também se insere no mundo e interpreta, a partir das suas vivências e experiências, em um movimento de se apropriar e externar de distintas formas, muitas vezes nos surpreendendo, como um modo particular de transformar o mundo.

A escola tem uma influência significativa no que diz respeito ao desenvolvimento e constituição da cultura infantil. Levando em conta este ambiente como um microssistema (BRONFENBRENNER, 1996) que pode promover a convivência dos educandos com distintas realidades e a interagir com seus pares. Nos primeiros anos do Ensino Fundamental, determinadas interconexões são condicionantes importantes para o desenvolvimento e a aprendizagem da criança.

Outro fator que pode influenciar o desenvolvimento da criança são os eventos que ocorrem nos ambientes em que elas vivenciam suas experiências, ou seja, "[...] A habilidade da criança de aprender a ler nas séries iniciais pode depender tanto de como ela é ensinada como da existência e natureza dos laços entre a escola e a família" (BRONFENBRENNER, 2011, p. 87). No atual sistema de ensino de nove anos, a partir da implementação da progressão continuada pela Lei Federal n. 11.114, a criança não reprova até o terceiro ano do Ensino Fundamental, pois este é o ciclo da alfabetização e a crianças é avaliada através de pareceres descritivos. A partir dessa etapa, é que ela tem que aprender a lidar com a possibilidade de reprovação quando não atinge os requisitos mínimos, geralmente relacionados à leitura e escrita, para progredir para o quarto ano. A pesquisa realizada apresenta o "olhar ecológico", a "leitura da realidade", as percepções das crianças sobre o processo de ensino e aprendizagem, em que expressam as suas impressões e sentimentos sobre a aprovação e a reprovação dentro do ambiente. 


\section{METODOLOGIA}

O estudo tem como base teórica e metodológica a Bioecologia do Desenvolvimento Humano (BRONFENBRENNER, 1996; BRONFENBRENNER; MORRIS, 1998). A Inserção Ecológica (CECCONELLO; KOLLER, 2004) será o método utilizado desde os primeiros contatos com os sujeitos a serem investigados, com a intenção de se criar um vínculo, ou seja, para que o pesquisador estabeleça uma relação mais próxima com o contexto de pesquisa, mas que aos poucos se torne pertencente aos ambientes de pesquisa.

A principal característica da Inserção Ecológica é acontecer em ambientes naturais. A pesquisa ocorreu em uma escola pública em duas etapas: a primeira etapa

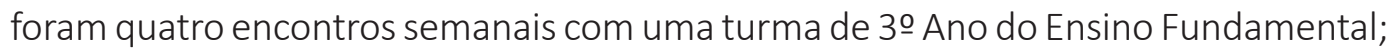
e a segunda etapa, no ano seguinte, com quatro crianças da primeira etapa, sendo duas cursando o quarto ano e duas que reprovaram e permaneceram cursando o terceiro ano. As crianças participantes da pesquisa foram ao total 23, entre 9 e 12 anos. Para a segunda fase, da pesquisa, participaram quatro crianças, uma menina de 10 anos, dois meninos também de 10 anos e um de 11 anos.

Na pesquisa com as crianças, é preciso elaborar estratégias diversas e diferenciadas para a participação efetiva dos sujeitos. Para isso, foram elaboradas atividades de interação com as crianças. Através de atividades lúdicas, observações, anotações em diário de campo e posteriormente a conversa realizada com as crianças, foi possível conhecer o seu pensamento crítico referente ao seu processo de escolarização.

Tendo como base a proposta de Cruz (2008), foi criada uma atividade lúdica para ser aplicada a entrevista com as quatro crianças que irão participar. Trata-se de uma "brincadeira de entrevistador e entrevistados", em que as perguntas serão realizadas de forma divertida, para distanciar o peso e o desinteresse que uma entrevista direta pode ocasionar para as crianças, ainda assim, não se perdendo o caráter de seriedade para com os dados adquiridos.

As interações foram gravadas e transcritas na íntegra, e os dados analisados qualitativamente seguindo os passos da Teoria Fundamentada nos Dados ou Grounded Theory (YUNES; SZYMASNKI, 2005). A Grounded Theory é um ponto metodológico de análise dos dados, o qual se compreende como uma interação com os dados, favorecendo assim uma imersão nas informações adquiridas. 


\section{DESENVOLVIMENTO}

A partir da análise dos dados, emergiram categorias e subcategorias sobre as percepções das crianças acerca do processo de aprendizagem. Essas percepções apontam para um olhar crítico sobre as estratégias de ensino, bem como os sentimentos com a aprovação e reprovação nesse processo. Essas análises são apresentadas na sequência.

Há diversos fatores que surgiram nas falas das crianças que expressam sentimentos e percepções sobre o processo de aprendizagem. Parece relevante o fato de crianças pensarem e ressaltarem a opinião de como diferentes formas de ensinar são importantes para o aprendizado das crianças no contexto escolar. - Tem que ter o estudo normal, mas entre uma coisa e outra, tem que ter uma brincadeira, pois isso é o que mais chama a atenção de uma criança. E seguiu: - As coisas difíceis, se tornam mais fáceis com brincadeiras. (D). A mesma menina, no semestre seguinte, nas atividades individuais, continuou com a mesma opinião a respeito das diferentes possibilidades de ensino, especificando ainda melhor: - Eu acho que o que mais atrai as crianças pra aprender é a brincadeira, tipo, que a gente pode aprender brincando, alguma coisa, tipo, um vez que a professora M... fez a gente virar um relógio pra gente aprender as horas, ou pintando também, desenhando (D).

As outras crianças ressaltaram ainda sobre as aulas: - Mais aula de Educação Física [Risos]. Poderia ter também armários pra cada um e... ainda, mais que armários, em vez de cadeiras, poltronas, que são mais confortáveis. (E) - Que a gente aprendesse coisas diferentes do que a gente aprende. (A).

$\mathrm{Na}$ fala dos participantes do estudo, fica evidente o olhar atento das crianças sobre as estratégias de ensino dos professores, em que destacam a importância da realização de atividades lúdicas, com movimento e expressão das múltiplas linguagens, para a motivação e promoção da aprendizagem da turma. As crianças pedem algo diferente do que geralmente é trabalhado com elas, melhor dizendo, como elas expuseram acima, atividades diferenciadas voltadas para a aprendizagem. As crianças sabem o que querem e sabem diferenciar uma aula lúdica de uma aula tradicional, em que a aprendizagem é centrada na expressão da escrita e oralidade (MORAES, 2009).

Estratégias pedagógicas pensadas para as crianças e construídas com elas ampliam as possibilidades de aprendizagem e são maneiras de elas se assumirem como sujeitos críticos desde pequenas. Fala-se muito na constituição de sujeitos críticos para atuarem e transformarem o mundo, porém, percebemos com esta pesquisa que devemos apresentar situações para as crianças pensarem determinadas problemáticas e conseguirem tomar decisões desde a primeira infância. 
$\mathrm{Na}$ atividade dos quadrinhos sobre a escola, o tema aprendizagem que apareceu em uma das histórias também chamou a atenção das crianças. O aluno "O" disse: - Uhum. É só um quadrinho. Ele tá sentado na sala e sai da outra janela um balãozinho que diz: "Que tédio"! Perguntei a eles o que será que estava acontecendo na sala para aquele aluno achar um tédio e quase todos responderam ao mesmo tempo: - Prova! Em seguida, o aluno E, salientou sobre a prova: - É chato, mas é bom pra ganhar nota.

Percebemos uma crítica da criança que fez o quadrinho em relação às muitas horas em que as crianças ficam fazendo coisas mesmas atividades e ao modelo de avaliação adotado pelos professores, baseados em notas e resultados definitivos e imediatos. Na percepção das crianças, as aulas, muitas vezes, não apresentam atrativos que motivem os educandos a participarem com maior entusiasmo das atividades.

Ainda perguntamos se eles gostariam de ter uma aula diferente ou se gostariam de alguma coisa fosse modificada nas aulas e obtivemos as seguintes respostas: Do "E": - Educação Física. Do "O": - Aula de desenho. Da "D": - Podia fazer... ãh... aquele tipo de aula que a gente aprende brincando. Em outro momento, as crianças responderam diante da questão "O que deve ter em uma aula para ser agradável e o aluno consiga aprender?"

- tem que ter alegria em estudar, outras coisas, como Português, Matemática, Estudos Sociais, Ciências. Seria bom também ter computadores, na sala de aula e não uma vez por semana, pra gente pesquisar sobre as coisas pra gente entender melhor. (E) - Um dia pra criança poder brincar um pouquinho, pra se entreter e não ficar preocupada só com o estudo e conteúdo. (A).

Conversando com a turma sobre a história do Menino Maluquinho, perguntamos se esse aluno merece reprovar de ano, pois ele tirava dez em todas as disciplinas, mas zero no comportamento. A educanda " $D$ " traz a seguinte resposta: - Eu acho que não né. Eu acho que tem que passar e ensinar ele de um outro jeito. Em outro momento, essa mesma educanda disse: - Ah, eu acho que os pais devem conversar com ela, pra tentar explicar pra ela o que tá acontecendo, pra ela entender. E seguiu: - Eu acho que tem que ensinar ela, não pode deixar de castigo, porque senão, ela vai querer fazer mais e mais e mais. Mas eu acho que tem que explicar pra ela que não é assim que funcionam as coisas, que ela tem que estudar e seguir, se comportar.

É perceptível com essas falas, que as crianças apresentam um olhar ecológico, baseado na compreensão sobre alguns fatores condicionantes da aprendizagem e uma sensibilidade sobre as diferentes situações comportamentais de outros alunos. 
Em um dos encontros, surgiu o assunto sobre brigas dos pais e desemprego, então perguntamos se isso poderia atrapalhar a aprendizagem de uma criança e uma menina respondeu: - Atrapalha, porque ele pode ficar triste, entrar em depressão, às vezes. (D). No semestre seguinte, voltando à mesma questão nos encontros individuais, obtivemos as seguintes respostas:

- Brincar muito, não fazer nada e ainda assim, os pais que não dão educação em casa e que não ajudam o filho em casa, nas matérias que ele não entende, aqueles que dizem assim: "Não vou te ajudar, porque é tu que tem que aprender, não é a gente" e não tão nem aí pro filho. (A).

Na conversa sobre o que pode dificultar a aprendizagem de uma criança, as crianças apontaram:

- Eu acho que a criança não querer fazer nada em sala de aula. Às vezes, a mãe não quer ajudar em nada, diz que o problema é dele, se rodou, rodou, o problema não é meu, é isso que acontece, só grita com a criança e diz: "Vaifazer tu, porque quem tá estudando é tu". E alguém que morre, ou perde o emprego, não tem dinheiro pra comprar comida pra dentro de casa e só. (E). - Eu acho que pai e mãe brigando em casa, ou... acho que é isso, pai e mãe brigando em casa, ou alguém morreu, essas coisa do tipo. (D).

Elas relataram que não se deve punir o aluno que apresenta um comportamento agitado ou agressivo, e sim pensam que se deve conversar para se entender o problema que pode estar causando esse comportamento. As crianças apontam que a escola e a família precisam rever as estratégias de ensinar e que essas ações podem ter impacto no processo de aprendizagem delas. Segundo Corsaro (2011), as crianças refletem sobre seu presente e futuro através de brincadeiras, como realizado durante os encontros, nos quais, a ludicidade foi presente.

As crianças relatam que a escola não é o único ambiente educativo citando outros contextos como a família, comunidade, religião, não espaço da rua. Essas crianças compreendem que o processo de aprendizagem escolar deve ser complementar ao processo que ocorre nos outros contextos de interação e convívio.

- a gente aprende com os nossos pais, na rua, com tudo que a gente olha, a gente tá aprendendo. A gente aprende toda a vida, a gente tá sempre aprendendo. Pela rua, quando vejo algumas pessoas ajudando as outras, na igreja, com as crianças de outra escola também e etc. (E). - A gente aprende em casa, na igreja e com outras pessoas da família também. (A). - Em casa... Uhnnn... É, em casa assim, com as pessoas, pai, mãe, irmão... Porque eu acho que faz parte assim, eles nos ensinarem o que tem que fazer. Como eles são mais velhos, eles sabem mais as coisas. (D). - Ãh, tem vezes que minha mãe 
passa um monte de coisas pra mim responder, minha mãe, minha irmã, o pai, outros ensinamentos. ( $\mathrm{Y}$ ).

É possível notar que as crianças participantes do estudo não menosprezam as aprendizagens dos diferentes microssistemas que frequentam, mas ressaltam a escola como um lugar importante para o seu desenvolvimento, de conviver com outros sujeitos, de aprender conteúdos, ou diante do que a família não consegue dar conta. Assim, Charlot (2013, p. 230), esclarece:

A escola foi, de início, um lugar de instrução, isto é, lugar de transmissão de um saber que não tinha curso sociedade sob uma forma imediatamente assimilável. [...] As escolas dispensaram um saber de tipo técnico. Esse saber desempenhava certo papel na formação da personalidade da criança, mas o essencial da educação era recebido fora da escola, na família e na sociedade. [...].

Ao escutar o que as crianças estão dizendo, estamos valorizando-as como pessoas em desenvolvimento e a sua constituição do sujeito crítico. Este estudo aponta que as crianças percebem o processo de aprendizagem e seus condicionantes, com destaque para o olhar ecológico sobre o papel dos contextos, as estratégias de ensino adotadas e as dificuldades enfrentadas pelos educandos nesse processo. O contexto escolar, através dos professores e equipe diretiva, devem estar atentos aos discursos das crianças, que podem apontar indícios importantes para os encaminhamentos pedagógicos diante das dificuldades no processo de ensino e aprendizagem. Percebo cada vez mais a necessidade de as crianças e jovens terem voz dentro desses ambientes em que elas passam algumas horas de seus dias.

Embora as crianças sejam frequentemente utilizadas para organizar o discurso, as vozes das crianças raramente são ouvidas [...]. Contudo, parece haver uma preocupação muito menor com as vidas das crianças no presente - e com suas infâncias -, especialmente com as infâncias das classes trabalhadoras e das crianças pobres. (CORSARO, 2011, p. 98).

De acordo Lisboa e Koller (2004), o papel da escola, que já é bastante discutido no sentido de ser um espaço de proteção para seus educandos, no que se refere ao desenvolvimento infantil pode influenciar positivamente ou negativamente, dependendo das interações promovidas nesse contexto ecológico. Acredito que, para uma influência positiva, um fator importante é a promoção da democracia dentro do espaço escolar, enquanto princípio da Educação Ambiental Crítica, através da escuta as vozes de seus educandos, do reconhecimento das diferenças e condicionantes no processo de aprendizagem, e do respeito aos seus interesses e desejos.

Outra categoria que emerge do olhar das crianças participantes deste estudo sobre o processo de aprendizagem se refere aos sentimentos e impressões diante 
da aprovação no contexto escolar. Todas as crianças que participaram da pesquisa ressaltaram a aprovação como a representação do sucesso no processo de aprendizagem, o resultado mais esperado. Obter o resultado positivo através da aprovação no ano letivo para elas, é a melhor sensação antes do início das férias.

Logo no começo do encontro, surgiu o assunto que alguns ressaltaram que gostariam de serem meus alunos no próximo ano letivo e uma aluna falou: - Sim, mas tem que se esforçar. (K). Esta fala sugere que para ela, aprovar significa que há a necessidade de esforço do aluno, que precisa dedicação e "trabalho" para que a a provação aconteça. Seguindo a conversa, o aluno " $\mathrm{C}$ ": - Porque às vezes tem coisas fáceis e às vezes tem coisas dificeis. (C). E assim, as crianças desejam a aprovação, criam uma grande expectativa a respeito e tem a esperança de aprovar até os últimos dias de aula. Isso fica claro, quando voltamos o olhar para o que aponta a aluna " $\mathrm{L}$ " em uma atividade de desenho em que tinham que representar as suas expectativas: - Eu desenhei que eu queria passar de ano. Perguntei a ela se esse desejo tinha acontecido e ela continuou: - Passei direto. Então quis saber dela como se sentiria se tivesse passado com exame e ela disse: - Eu ficaria com medo de rodar de ano. Se eu tivesse que fazer exame, é porque não sei alguma matéria.

$\mathrm{Na}$ vez de outro aluno, o C, ele salientou em seu desenho uma expectativa parecida com a da colega anterior, o desejo de aprovar no final do ano: - Eu passando de ano e os meus amigos juntos. Perguntei se ele tinha aprovado e ele respondeu: Passei, mas fiquei em recuperação em Matemática. Há uma grande expectativa de ser aprovado com seus amigos e um sentimento ruim, talvez de insegurança ou incapacidade, quando lembra que aprovou precisando realizar o exame final em Matemática.

Nos encontros individuais, as crianças também relataram uma grande expectativa por aprovar de ano: - Meu maior desejo é que eu passe, seja um aluno bom e que tenha vários amigos, pra no futuro eu ter outros também. (E). A criança A, Y e a D também afirmaram sua expectativa da mesma forma: - Passar! Com certeza, passar! Interessante refletir sobre como as crianças expressam esse sentimento e constroem expectativa de sucesso ou medo do fracasso nos anos iniciais do Ensino Fundamental, principalmente quando se refere ao primeiro momento em que vivenciam essa situação ao final do ciclo de alfabetização, na passagem do terceiro para o quarto ano. É curioso o fato que nos anos anteriores não vivenciaram essa possibilidade de aprovação e reprovação. Ao chegar no final do terceiro ano, essa se transforma em uma das principais expectativas das crianças.

[...] As reações da criança durante este processo podem variar muito e dependem de diversos fatores, de forma que a compreensão da adaptação dela 
requer uma análise completa de todos os fatores envolvidos relacionados tanto à história da criança, suas características individuais, seu ambiente familiar como também às características do educador e da instituição de ensino. [...]. (RAPOPORT, 2009, p. 27).

O educando "E" falou da sensação da aprovação ao passar do terceiro para o quarto ano do Ensino Fundamental:

- Muito bem. Eu me sentia feliz quando tirava uma nota boa na prova e me sentia triste quando eu tirava uma nota ruim. Eu me senti muito feliz, porque minha mãe chegou e eu perguntei como eu fui, aí ela fez assim (expressão de descontentamento) e a ela disse, "passasse"! Aí fiquei muito feliz. (E).

Diante do processo de progressão nos anos iniciais do Ensino Fundamental, as expectativas e os sentimentos das crianças sofrem alterações, muitas vezes, condicionados pelas expectativas dos adultos e pelas avaliações que realizam para a comprovação (ou não) das competências leitura e escrita apreendidas. As crianças, ao incorporarem essas preocupações sobre a aprovação e reprovação no fim do primeiro ciclo, como é o caso dos sujeitos investigados, percebem as consequências que envolvem esses resultados para as suas vivências e experiências no contexto escolar.

Nessa perspectiva, as crianças no terceiro ano já demonstram muito receio diante da reprovação. Ao questioná-las sobre o assunto, elas apresentaram respostas bem diretas e rápidas: - Que eu rode, perca os meus amigos e tenha que fazer tudo de novo. (E). - Rodar! (A). - De eu rodar! (D). - Acho que rodar de ano! (Y).

É importante ressaltar também a fala das crianças que já conhecem a reprovação escolar, pois estão repetindo o terceiro ano, e como conseguiram superar esse resultado. O educando " $\mathrm{A}$ " disse como se sentiu quando reprovou e em seguida falou da sensação que teve quando aprovou para o quarto ano:

- Muito mal. - No outro ano, quando eu passei, eu disse: - E aí, vó, passei? E a minha irmã disse: - Não, "rodasse"! E aí elas riram, eu tinha passado. Eu tava com medo que minha vó me batesse. Mas ela me deu um abraço, por causa que eu tinha passado. (A).

Os resultados do processo avaliativo podem provocar sentimentos de ansiedade e inseguranças nas crianças que vivenciam. Quando uma criança reprova e sofre uma pressão da família, por exemplo, pode se sentir incapaz, se frustrando. A mesma criança, se encorajada a seguir, sem ser culpada pelo resultado negativo, pode superar a reprovação e alcançar o resultado positivo. A aprovação do aluno " $A$ " no ano seguinte aponta para a resiliência diante de uma situação de vulnerabilidade (YUNES; SZYMANSKI, 2001), como uma superação diante da reprovação escolar. A 
resiliência é um processo, desenvolvido no ser humano, de acordo com o ambiente, para suportar e superar situações ruins, apontando, então, que a resiliência ocorre quando os sistemas de proteção agem em distintos pontos do desenvolvimento do indivíduo e em diferentes contextos. As experiências dos sujeitos, neste caso as crianças participantes do estudo e que vivenciaram a situação de reprovação, mostram a profunda capacidade de resistir, se adaptar e criar situações para superar problemas e se desenvolver. Nesse caso, cito como exemplo, a reprovação, que é um exemplo claro nesse trabalho, de superação de uma situação que causou estresse, em busca do resultado positivo, tão esperado para essas crianças.

As crianças apontam que o principal motivo para a reprovação é a falta de esforço e estudo do educando: - Eu queria estudar com todo mundo que tá aqui, mas não deu muito certo não! Deu certo 20\%. A minha amiga rodou. (C). Ao perguntar para uma das alunas o que ela achou da colega ter reprovado, ela respondeu: - Ah! Achei ruim. Acho que ela não estudou. (M). Em continuidade a conversa perguntei o que acontece com quem não estuda, e um aluno respondeu: - Ele vai acabar rodando de ano e vai perder tempo da vida dele. (D).

As crianças investigadas pensam a reprovação como algo que acontece com quem não sabe o conteúdo, por exemplo, mas também, apresentam um pensamento contraditório em alguns momentos, pensam a reprovação como algo capaz de prejudicar um educando. A turma toda citou o que eles pensam que pode acontecer com quem não é um "educando sem dificuldades escolares": - Ele roda de ano. Fui perguntando o porquê e: - Porque ele não sabe de nada. (E). - Porque ele não estuda. (A).

$\mathrm{Na}$ brincadeira de repórter, realizada individualmente, as respostas foram mais claras sobre como eles pensam a reprovação:

- Nunca! Porque é muito chato ter que ver tudo aquilo, ver um monte de aluno novo e aí não se encaixa muito bem na turma. Fazer de novo e de novo, tudo aquilo que tu já aprendeu. (E). - Quando a criança não quer fazer nada em sala de aula e debocha da professora e também fica só brincando na sala de aula e atrapalhando as outras crianças e quando não quer aprender. Aí, ela tem que reprovar, porque ela é uma pessoa muito má. (A). - Quando ela não sabe as coisas e quando falta muito. (Y). - Olha, eu acho que depende, né, por causa que se não passou, foi porque não entendeu as coisas e se ela fizer o mesmo ano de novo, ela pode entender. E por outro lado, é ruim, porque ela vai se atrasar nos estudos. (D).

A reprovação pode gerar um momento de estresse e tristeza para a criança. Ao final do primeiro ciclo, algumas crianças não apresentam os requisitos mínimos para 
aprovação. A ansiedade dos familiares e da própria criança, bem como o sentimento negativo propiciado pela reprovação, podem se tornar condicionantes para que o sentimento de fracasso e incapacidade prevaleça sobre a possibilidade e motivação para a superação das dificuldades de aprendizagem.

Segundo Koller (2004), suportar uma situação ruim não pode ser visto como um risco a priori, mas como um processo que faz parte da vida. A frustração gerada pela reprovação não pode ser transformada em um discurso sobre fracasso escolar, e sim como uma situação a ser superada para a promoção do desenvolvimento infantil. Podemos citar o exemplo de dois educandos, O " $\mathrm{A}$ " e o " $\mathrm{Y}$ " que participaram dos encontros individuais, que reprovaram e, no ano seguinte, conseguiram a aprovação para o quarto ano do Ensino Fundamental. Nesses casos, a resiliência manifestou a superação e faz com que o sujeito acredite em si, se perceba com um ser competente e forte para superar o obstáculo (CECCONELLO, 2003; HUTZ; KOLLER; BANDEIRA, 1996; YUNES, 2003; YUNES; SZYMANSKI, 2001, TAVARES, 2001), dependendo da interação entre as características individuais, da abordagem pedagógica da escola, do apoio e incentivo da família. No caso da aprovação das crianças " $A$ " e " $Y$ ", alguns fatores modificados dentro do contexto podem ter auxiliado nessa superação: $A$ mudança de professor, de colegas, aulas reforço, a maior participação da família no ambiente escolar, maior preocupação em estudar as atividades trabalhadas em aula e outros tantos. O educando "E" fala sobre a importância do papel da professora na avaliação e acompanhamento diário para a aprovação: - Pra ela aprovar tem que ser todos os dias, tipo um acompanhamento no desenvolvimento dela. Todos os dias, a professora tem que ajudar os alunos que não entendem bem pra aí, se formar e aí depois, conseguir um emprego e ter uma vida. (E).

Portanto a situação de superação de determinadas situações frustrantes na infância é fator que contribui para o seu desenvolvimento. Como seres humanos, lidamos a todo momento com situações de crise e, consequentemente, a sua superação. Lembrando que as bases da resiliência não são fixas, elas podem ser distintas, tanto ambientais quanto conjunturais (KOLLER, 2004), por isso, precisamos acreditar no potencial dos seres humanos, assim como também oportunizar ambientes saudáveis, que possibilitem a busca da felicidade e o bem-estar dos sujeitos.

Diferentemente do que muitos adultos acreditam, as crianças têm um olhar e constroem expectativas a respeito da situação na qual estão imersas e sabem apontar o que pode ser melhor para elas. Muitas vezes, percebemos que os espaços voltados para as crianças são pensados apenas a partir do olhar do adulto. Esse adulto até 
pode organizar tudo da melhor maneira possível, mas, ainda assim, está construindo para as crianças, e não com elas. Penso que, se um espaço será destinado às crianças, por que não decidir como deve ser esse espaço juntamente, professor e educandos?

Nesta pesquisa, elas tomaram posição sobre situações que ocorrem ou ocorreram em aula e puderam, mesmo que não acostumadas a falar, expressar com coerência-que gostariam de aprender em um ambiente diferente do que é possibilitado a elas. "[...] percebemos que, ao definir uma dada organização do espaço, os adultos comunicam significados sobre o que fazer, como fazer, quando fazer, onde fazer e com quem fazer [...]" (FRANCISCO; ROCHA, 2008, p. 310-1). Deveria ser no tempo/espaço da escola que as crianças experimentariam com mais intensidade a constituição de sua autonomia.

\section{CONSIDERAÇÕES FINAIS}

O processo da constituição do sujeito crítico/reflexivo envolve a concepção de que somos seres históricos, culturais e, ao mesmo tempo, naturais, e a educação é uma das partes principais da ação humana como forma de conferir sentido e novas compreensões.

As atividades lúdicas que foram realizadas com as crianças proporcionaram uma maior aproximação com as crianças, de uma forma distinta da habitual. O processo de desenvolvimento das atividades com as crianças proporcionou a elas relatarem e apontarem suas percepções sobre o tempo que passam dentro da escola. Algumas falas surpreendem pelas impressões apresentadas pelas crianças, por demonstrarem a seriedade e complexidade diante de algumas problemáticas que as afligem, como a culpabilização pela reprovação e as dificuldades no processo de aprendizagem.

Os participantes compreendem que o processo de aprendizagem é influenciado pelas condições de vida e emocionais dos sujeitos aprendentes. Reconhecem como positivo o apoio da família no processo de escolarização e pensam que uma criança alcança mais facilmente o sucesso, quando sua família é presente na escola, se preocupa com a lição, quando olha seu material escolar e a ajuda. Ao mesmo tempo, algumas dessas crianças mencionam também que a ausência familiar pode ser um fator que ajuda na reprovação da criança, assim como alguns problemas familiares, como desemprego, violência, falecimento de algum membro familiar, podem afetar o desenvolvimento escolar da criança.

Os resultados desta pesquisa apontam que as crianças constroem um olhar ecológico sobre seu processo de escolarização e sabem expressar os sentimentos 
de sucesso diante da aprovação ou frustração com a reprovação no primeiro ciclo dos anos iniciais do Ensino Fundamental. Portanto as crianças precisam ter direito de manifestarem suas vozes e vivenciarem experiências em suas infâncias em um ambiente de oportunidades e proteção, seja na escola, família, bairro, outras instituições, entre outros.

\section{REFERÊNCIAS}

BRONFENBRENNER, U. Bioecologia do desenvolvimento humano: tornando os seres humanos mais humanos. Porto Alegre: Artmed, 2011.

. A ecologia do desenvolvimento humano. Experimentos naturais e planejados. 2. ed. Porto Alegre: Artes Médicas, 1996.

BRONFENBRENNER, U.; MORRIS, P. The ecology of developmental processes. In: DAMON, W. (Org.). Handbook of child psychology. New York: John Wiley Sons, 1998. V. 1.

CECCONELLO, A. M. Resiliência e vulnerabilidade em famílias em situação de risco. 2003. Tese (Doutorado em Psicologia do Desenvolvimento)- Universidade Federal do Rio Grande do Sul (UFRGS), Porto Alegre, RS, 2003.

CECCONELLO, A. M.; KOLLER, S. H. Inserção ecológica na comunidade: uma proposta metodológica para o estudo de famílias em situação de risco. In: KOLLER, S. H. (Org.). Ecologia do desenvolvimento humano: pesquisa e intervenção no Brasil. São Paulo: Casa do Psicólogo, 2004.

CHARLOT, B. A mistificação pedagógica: realidades sociais e processos ideológicos na teoria da educação. São Paulo: Cortez, 2013.

CORSARO, W. A. Sociologia da infância. 2. ed. Porto Alegre: Artmed, 2011.

CRUZ, S. H. V. A criança fala: a escuta de crianças em pesquisas. São Paulo: Cortez, 2008.

DELGADO, A. C. C.; MULLER, F. Infâncias, tempos e espaços: um diálogo com Manuel Jacinto Sarmento. Currículo sem Fronteiras, v. 6, n. 1, p. 15-24, jan./jun. 2006.

FRANCISCO, Z. F.; ROCHA, E. A. C. "Zé, tá pertinho de ir pro parque?" O tempo e o espaço do parque em uma instituição de Educação Infantil. In: CRUZ, S. H. V. (Org.). A criança fala: a escuta de crianças em pesquisas. São Paulo: Cortez, 2008. p. 307-11.

FREIRE, P. Pedagogia da autonomia: saberes necessários à prática educativa. 25. ed. Rio de Janeiro: Paz e Terra, 1996.

HUTZ, C. S.; KOLLER, S. H.; BANDEIRA, D. R. Resiliência e vulnerabilidade em crianças em situação de risco. In: KOLLER, S. H. Aplicações da Psicologia na melhoria da qualidade de vida. Porto Alegre, RS: ANPEPP, 1996. (Coletâneas da ANPEPP, n. 12, p. 79-86).

KOLLER, S. H. Ecologia do desenvolvimento humano. São Paulo: Casa do Psicólogo, 2004. 
LISBOA, C. S. M.; KOLLER, S. H. O microssistema escolar e os processos proximais: exemplos de investigações científicas e intervenções práticas. In: KOLLER, S. H. Ecologia do desenvolvimento humano. São Paulo: Casa do Psicólogo, 2004. p. 337-80.

LOUREIRO, Carlos Frederico Bernardo et al. Pensamento complexo, dialética e educação ambiental. São Paulo: Cortez, 2006.

MORAES, L. S. Interlocuções matemáticas na aprendizagem da leitura e da escrita. In: RAPOPORT, A.; SARMENTO, D. F.; NÕRNBERG, M.; PACHECO, S. M. A criança de seis anos: no ensino fundamental. Porto Alegre: Mediação, 2009. p. 83-90.

RAPOPORT, A. Adaptação ao primeiro ano do ensino fundamental. In: RAPOPORT, A.; SARMENTO, D. F.; NÕRNBERG, M.; PACHECO, S. M. A criança de seis anos: no ensino fundamental. Porto Alegre: Mediação, 2009. p. 23-35.

TAVARES, J. Resiliência e educação. São Paulo: Cortez, 2001.

YUNES, M. A. M. Psicologia positiva e resiliência: o foco no indivíduo e na família. Psicologia em Estudo, Maringá, PR, v. 8, número especial, p. 75-84, 2003.

YUNES, M. A. M.; SZYMANSKI, H. Grounded-Theory e a entrevista reflexiva: uma associação de estratégias metodológicas qualitativas para a compreensão da resiliência em famílias. In: GALIAZZI, M. C.; FREITAS, J. V. Metodologias emergentes de pesquisa em educação ambiental. Ijuí, RS: Ed. Unijuí, 2005.

. Resiliência: noção, conceitos afins e considerações críticas. In: TAVARES, J. (Org.). Resiliência e educação. 2. ed. São Paulo: Cortez, 2001. p. 13-42.

\section{Sobre as autoras:}

Marcia Soares da Silva: Pedagoga. Mestranda no Programa de Pós-Graduação em Educação Ambiental na Universidade Federal do Rio Grande (FURG). Professora da rede pública de ensino.E-mail: marcia.s.furg@gmail.com

Narjara Mendes Garcia: Pedagoga. Doutora em Educação Ambiental. Professora Adjunta no Instituto de Educação da Universidade Federal do Rio Grande (FURG). Professora Permanente do Programa de Pós-Graduação em Educação Ambiental. Pesquisa do Núcleo de Pesquisa e Educação da Infância (NEPE/FURG). E-mail: narjaramg@yahoo.com.br

\section{Recebido em fevereiro de 2017.}

\section{Aprovado para publicação em junho de 2017.}

